\title{
Acute conjunctivitis caused by an atypical chlamydial strain: Chlamydia IOL 207
}

\author{
T. FORSEY AND S. DAROUGAR
}

From the Subdepartment of Virology, Institute of Ophthalmology, University of London

SUMmARY A case of acute conjunctivitis in man caused by Chlamydia IOL 207 is described. Chlamydiae were isolated from the eye, and rising titres of type-specific antibodies to C. IOL 207, in serum and tears demonstrated an aetiological role for this agent. C. IOL 207 is an atypical chlamydial strain which serological studies suggest is widespread in some communities.

Chlamydia trachomatis causes a range of ocular diseases in man from trachoma in developing countries to sexually transmitted, oculogenital infections in developed countries. Infections by Chlamydia psittaci are usually confined to the animal kingdom, although sporadic cases of ocular infection in man have been reported. Exposure in the laboratory to $C$. psittaci agents as well as transmission from cats have been responsible for cases of human conjunctivitis. ${ }^{12} \mathrm{C}$. psittaci has also been isolated from a patient with keratitis and uveitis. ${ }^{3}$ Here we present a case of acute conjunctivitis in man caused by an atypical chlamydial strain, designated Chlamydia IOL 207. Serological evidence indicates that infection with this agent is common in some communities. $^{45}$ However, the site and natural history of these infections are unknown.

\section{Case report}

The patient was a 30-year-old male laboratory technician who was routinely handling chlamydial agents. He complained of redness, swelling of the right eye, and discharge for 2 days before attending the clinic. On examination a moderate degree of hyperaemia was seen in the bulbar conjunctiva, and moderate hyperaemia and papillary and follicular responses were observed in the palpebral conjunctiva of the right eye, the left eye being normal. A tentative diagnosis of a viral conjunctivitis was made. After collection of conjunctival swabs, blood, and tears, the patient was treated with $1 \%$ trifluorothymidine drops. One week later, 9 days from onset, the patient

Correspondence to Mr T. Forsey, Subdepartment of Virology, Institute of Ophthalmology, Judd Street, London WC1H 9QS. had developed a mild rhinitis, and symptoms in the right eye had worsened. The intensity of papillary and follicular reactions in the palpebral conjunctivae of the upper and lower lids was more severe (Figs. 1, $2,3)$. No abnormalities were detected in the cornea. At this stage a clinical diagnosis of chlamydial conjunctivitis was made, and the patient was treated with systemic doxycycline (at an initial dose of $300 \mathrm{mg}$ followed by $100 \mathrm{mg}$ daily for 3 weeks) and topical aureomycin ( 5 times daily for 6 weeks). Three days later, 12 days from onset, the signs and symptoms in the right eye had improved. During the course of infection in the right eye a mild inflammatory response was observed in the left eye. Seventeen weeks after onset the patient was asymptomatic. The intensity of

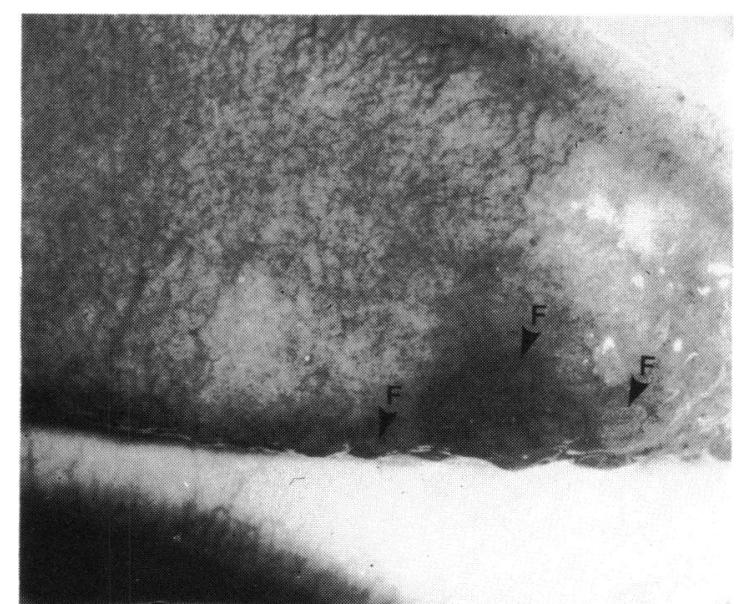

Fig. 1 Upper tarsal conjunctiva showing moderate papillary responses and follicles $(F)$. 


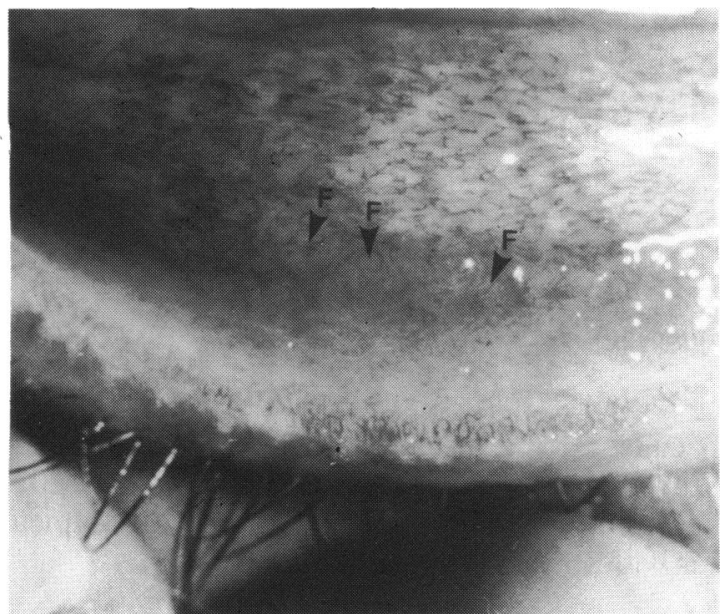

Fig. 2 Lower palpebral conjunctiva showing moderate papillary responses and follicles $(F)$.

clinical signs observed during the course of the disease is shown in Fig. 4.

Conjunctival swabs were collected from the right eye at 2 days and at 7 days from onset. Attempts to isolate chlamydiae in McCoy cells ${ }^{6}$ and viruses in tissue cultures ${ }^{7}$ were unsuccessful even after several passages. However, chlamydiae were isolated in the yolk sac of fertile hens' eggs $^{8}$ from both sets of specimens. These chlamydial isolates could not be propagated continuously in yolk sac nor transferred to tissue culture. Consequently these isolates were not serotyped.

Serum and tears were collected during the course of the infection and tested against a range of chlamydial serotypes in a microimmunofluorescence

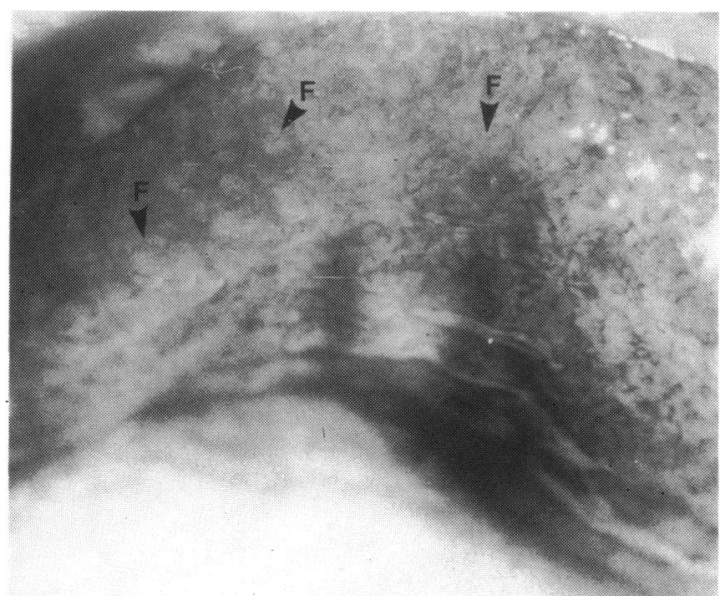

Fig. 3 Upper fornix conjunctiva showing moderate follicular responses $(F)$.

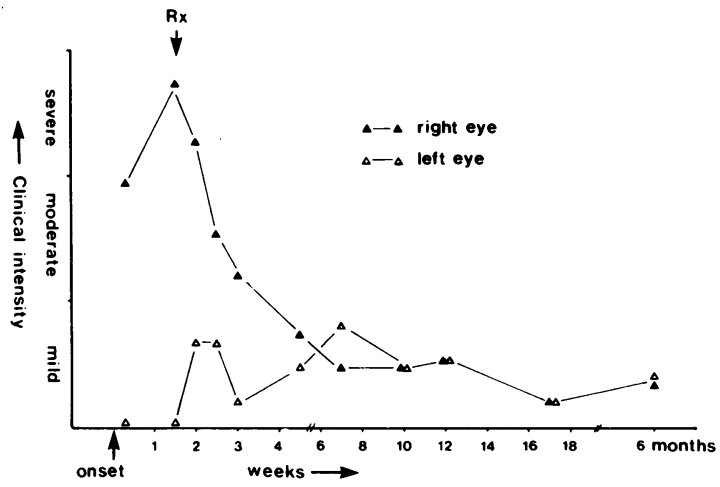

Fig. 4 Conjunctival inflammatory responses in the right and left eyes.

test. ${ }^{9}$ Also tested was a sample of serum collected from this patient 2 years previously.

Type-specific IgG antbodies to $C$. IOL 207 were detected at a titre of $1 / 16$ in the preinfection serum sample. The level of these serum antibodies rose to $1 / 512$ during the infection and dropped back to $1 / 16$ after 6 months (Fig. 5). No IgM antibodies were detected.

In tears collected from the right eye type-specific IgG and IgA antibodies to $C$. IOL 207 appeared at 7 days from onset of disease and rose to titres of $1 / 128$ and $1 / 64$ respectively (Fig. 5). The titres of these antibodies were closely related to the intensity of clinical signs in the right eye (Figs. 4, 5). IgA disappeared after treatment when the signs became mild at 7 weeks from onset. IgG disappeared from the tears when the patient became asymptomatic at 17 weeks from onset. No antibodies were detected in tears collected from the left eye.

No antibodies were detected against $C$. trachomatis or $C$. psittaci serotypes in serum or tears.

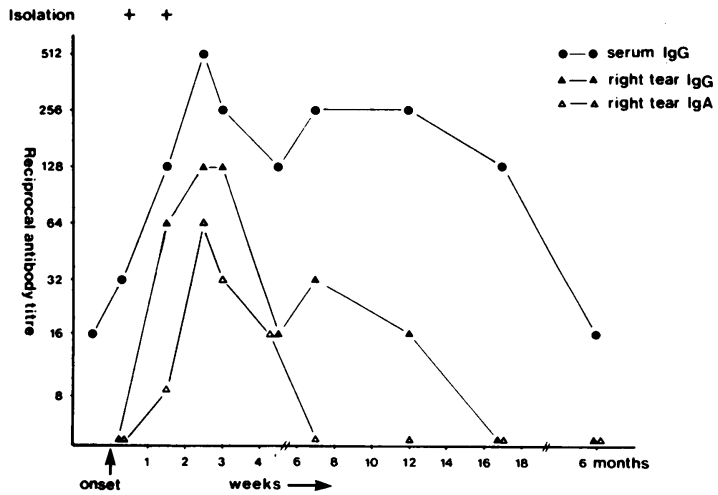

Fig. 5 Isolation of chlamydiae and detection of type specific antibodies to Chlamydia IOL 207 in serum and tears. 


\section{Discussion}

Here we present a case of conjunctivitis in man caused by Chlamydia IOL 207. A chlamydial agent was isolated from the right eye on 2 occasions in the yolk sac of embryonated eggs. This agent was not serotyped owing to difficulty in propagating the organism in eggs and tissue culture.

However, the rise and fall in the titres of antibodies specific for $C$. IOL 207 in sera and tears from the patient confirmed that $C$. IOL 207 was the cause of the conjunctivitis. The lack of IgM in serum may be a result of previous exposure to this organism. This was demonstrated by the presence of IgG to $C$. IOL 207 in the serum sample taken 2 years previously. It has been shown in experimental chlamydial infections that after primary infection with a particular serotype reinfection with the same serotype produces an anamnestic response in serum IgG but no recall of IgM. ${ }^{10}$

The presence and titres of antibodies in the tears from the infected right eye correlated well with the intensity of inflammation in that eye. This observation confirms findings that the presence of antichlamydial antibodies in tears is indicative of active ocular infection. ${ }^{11}$

C. IOL 207 is an atypical chlamydial strain with growth characteristics similar to those of $C$. trachomatis but whose inclusions do not stain with iodine stain. The organism is sensitive to sulphadiazine. It was originally isolated by serial passage in embryonated hens' eggs from the eye of an Iranian child with trachoma. ${ }^{4}$ This agent is antigenically similar to an isolate designated TW 183 isolated from a Taiwanese patient with 'dubious trachoma.' 412

Experimental inoculation of a baboon has shown that $C$. IOL 207 can cause mild urethritis and conjunctivitis. ${ }^{13}$ In that study tissue culture proved not to be sensitive for the reisolation of $C$. IOL 207, and the agent was reisolated only after several passages in the yolk sac of fertile eggs.

In London antibodies to this agent have been detected in patients with oculogenital infections ${ }^{4}$ as well as in large numbers of male and female 'healthy' blood donors. ${ }^{5}$ We have also found that antibodies to C. IOL 207 are uncommon in children under the age of 5 but increase in prevalence after that age (unpublished observations). Our seroepidemiological surveys have also shown that infection by $C$. IOL 207 is common among populations in Africa and the Middle East (unpublished observations).
This case report demonstrates that Chlamydia IOL 207 is a human pathogen capable of causing acute conjunctivitis. Serological evidence suggests that infections with this organism are widespread in some communities. However, the lack of isolation data means that the epidemiology and natural history of these infections is still unknown. We believe that further work is needed to elucidate the role of $C$. IOL 207 in diseases of the eye and other organs.

\section{References}

1 Schachter J, Arnstein P, Dawson CR, Hanna L. Human follicular : conjunctivitis caused by infection with a psittacosis agent. Proc Soc Exp Biol Med 1968; 127: 292-5.

2 Ostler HB, Schachter J, Dawson CR. Acute follicular conjunctivitis of epizootic origin. Arch Ophthalmol 1969; 82: 587-91.

3 Darougar S, John AC, Viswalingham M, Cornell L, Jones BR. Isolation of Chlamydia psittaci from a patient with interstitial keratitis and uveitis associated with otological and cardiovascular lesions. Br J Ophthalmol 1978; 62: 709-14.

4 Dwyer R StC, Treharne JD, Jones BR, Herring J. Chlamydial infection. Results of micro-immunofluorescence tests for the detection of type-specific antibody in ccrtain chlamydial infections. Br J Vener Dis 1972; 48: 452-9.

5 Darougar S, Forsey T, Brewerton DA, Rogers KLI. Prevalence of antichlamydial antibodies in London blood donors. $\mathrm{BrJ}$ Vener Dis 1980; 56: 404-7.

6 Ripa KT, Mardh P-A. New simplificd culture techniques for Chlamyia trachomatis. In: Hobson D, Holmes KK, eds. Nongonococcal urethritis and related infections. Washington, DC: American Society for Microbiology, 1977: 323-7.

7 McSwiggan DA, Darougar S, Rahman AFMS, Gibson JA. Comparison of the sensitivity of human embryo kidney cells for the primary isolation of viruses from the eye. J Clin Pathol 1975; 28: 410-3.

8 Gordon FB, Harper IA, Quan AL, Treharne JD, Dwyer R StC, Garland JA. Detection of Chlamydia (Bedsonia) in certain infections of man. I. Laboratory procedures: Comparison of yolk sac and cell culture for detection and isolation. J Infect Dis 1969; 120: 451-62.

9 Treharne JD, Darougar S, Jones BR. Modification of the microimmunofluorescence test to provide a routine serodiagnostic test for chlamydial infection. J Clin Pathol 1977; 30: 510-7.

10 Wang S-P, Grayston JT. Local and systemic antibody responses to trachoma eye infections in monkeys. In: Nichols RL, ed. Trachoma and related diseases caused by chlamydial agents. Amsterdam: Excerpta Mcdica, 1971: 217-32.

11 Darougar S, Treharne JD, Minassian D, El-Sheikh H, Dines R, Jones BR. Rapid serological test for diagnosis of chlamydial ocular infections. BrJ Ophthalmol 1978; 62: 503-8.

12 Stephens RS, Tam MR, Kuo C-C, Nowinski RC. Monoclonal antibodies to Chlamydia trachomatis: Antibody specificities and antigen characterisation. J Immunol 1982; 128: 1083-9.

13 Darougar S, Monnickendam MA, El-Sheikh H, Treharne JD, Woodland RM, Jones BR. Animal models for the study of chlamydial infections of the cye and genital tract. In: Hobson D, Holmes KK, eds. Nongonococcal urethritis and related infections. Washington DC: American Socicty for Microbiology, 1977: 148-52. 